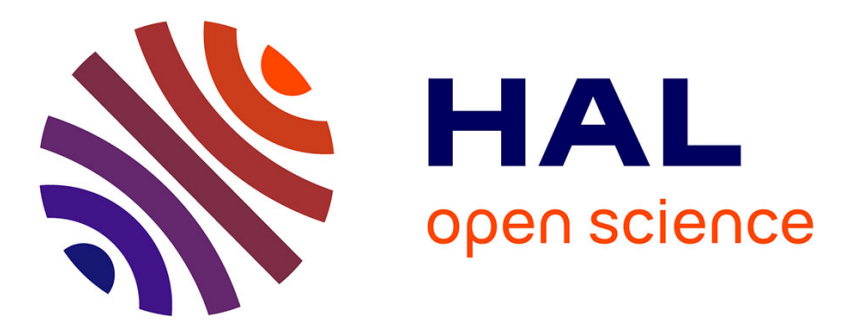

\title{
Experimental Determination of Fully-Coupled Kinematical and Thermal Fields at the Scale of Grains Under Cyclic Loading
}

Laurence Bodelot, Laurent Sabatier, Eric Charkaluk, Philippe Dufrenoy

\section{To cite this version:}

Laurence Bodelot, Laurent Sabatier, Eric Charkaluk, Philippe Dufrenoy. Experimental Determination of Fully-Coupled Kinematical and Thermal Fields at the Scale of Grains Under Cyclic Loading. Advanced Engineering Materials, 2009, 11 (9), pp.723-726. 10.1002/adem.200900035 . hal-00424948

\author{
HAL Id: hal-00424948 \\ https://hal.science/hal-00424948
}

Submitted on 20 Sep 2021

HAL is a multi-disciplinary open access archive for the deposit and dissemination of scientific research documents, whether they are published or not. The documents may come from teaching and research institutions in France or abroad, or from public or private research centers.
L'archive ouverte pluridisciplinaire HAL, est destinée au dépôt et à la diffusion de documents scientifiques de niveau recherche, publiés ou non, émanant des établissements d'enseignement et de recherche français ou étrangers, des laboratoires publics ou privés.

\section{(c)(1)}

Distributed under a Creative Commons Attribution| 4.0 International License 


\title{
Experimental Determination of Fully-Coupled Kinematical and Thermal Fields at the Scale of Grains Under Cyclic Loading
}

\author{
By Laurence Bodelot, Laurent Sabatier, Eric Charkaluk* and Philippe Dufrénoy
}

\begin{abstract}
Many isotropic metallic materials are made of an aggregate of grains of random crystallographic orientations. Among them, some are favorably oriented for plastic gliding with respect to the loading axis. This creates a local heterogeneity as these grains can exhibit plastic strains whereas others still undergo pure elastic response. ${ }^{[1]}$ Moreover, plasticity triggers the appearance of slip bands at the surface of the material due to the deformation along with a thermal dissipation which can be detected at the structure scale. Hence the material behavior under fatigue may be thermally and mechanically different from one grain to another. Works exploiting the dissipation due to plasticity under cyclic loading have already been published. They aim at studying the mean temperature of the whole specimen to account for its damage. This is the basis of the fatigue limit determination set up by Luong ${ }^{[2]}$ and also investigated by Curà et al. ${ }^{[3]}$ This information combined with a probabilistic model of fatigue also allows to predict fatigue scatter Doudard et al. ${ }^{[4]}$ Other research teams focus on the determination of heat sources from temperature measurements. ${ }^{[5]}$ Nevertheless all these studies take place at a macroscopic scale whereas phenomena arise at the grain scale. There is thus a lack of simultaneous data about the kinematic and thermal behaviors of the material at the mesoscopic scale of damage. Therefore, the objective of this work is the development of a method enabling an access to a fully-coupled measurement of both kinematic and thermal fields of the same zone at the grain scale. The full-field measurements methods are first presented, namely infrared thermography (IRT) for temperature fields measurements and digital image correlation (DIC) for strain fields measurements. Then necessary constraints and precautions to reach a fully-coupled recording are specified. Finally, kinematic and thermal results obtained during a cyclic loading performed on AISI 316L stainless steel are presented and discussed.
\end{abstract}

[*] Dr. L. Bodelot, Dr. L. Sabatier, Dr. E. Charkaluk, Dr. P. Dufrenoy

Laboratoire de Mécanique de Lille - UMR CNRS 8107 Cité Scientifique, Boulevard Paul Langevin, 59655 Villeneuve d'Ascq Cedex, France

E-mail: ric.charkaluk@univ-lille1.fr

\section{Experimental Setup}

\section{Thermal Measurements}

The camera used in this work is a Cedip Jade III. Its infrared sensitive part is a Focal Plane Array (FPA) of 320 by $240 \mathrm{InSb}$ detectors, cooled down at $77 \mathrm{~K}$ by a rotary Stirling and working in the spectral range from 3 to $5 \mu \mathrm{m}$. Its maximum frame rate in full frame is $170 \mathrm{~Hz}$ and the dynamic range of digital levels is 14 bits. This camera is used with a high magnification lens known as G1 since the spatial resolution matches the size of one detector, which is $30 \mu \mathrm{m} \times 30 \mu \mathrm{m}$. This leads to a $9.6 \mathrm{~mm} \times$ $7.2 \mathrm{~mm}$ observation zone but as the G1 lens induces optical distortions, the working zone is here narrowed to $5 \mathrm{~mm} \times 5 \mathrm{~mm}$.

To perform accurate quantitative IRT, a precise calibration must be performed, the emissivity of the object has to be determined and some precautions must be taken. Firstly, a calibration law, which gives a link between temperatures and thermal emissions, has to be established by exposing the detector array of the camera in front of an extended blackbody at different controlled temperatures. However each detector possesses its own behavior which is even different each time the camera is switched on; this is a particular drawback of FPA cameras. In a standard use, the response of each detector is corrected through Non-Uniformity Correction (NUC) and Bad Pixel Replacement (BPR) procedures but they tend to make local heterogeneities disappear. Nonetheless, the NUC and BPR procedures can be bypassed by the determination of a calibration law detector by detector. ${ }^{[6]}$ Moreover, as the calibration is influenced by many parameters (distance to the object, lens used, working temperature, integration time, frame rate, etc.), a new calibration is necessary for each test configuration $^{[7]}$ and each time the camera is switched on. Secondly, the emissivity of the object has to be determined. This can be realized through a classically used method which consists in a comparison between the radiation of the object and the one of an extended blackbody, both being at the same temperature. ${ }^{[8]}$ At last, for a better accuracy, the camera is turned on more than $4 \mathrm{~h}$ before beginning any measurements including calibration in order to avoid facing with thermal drift. The working place around the camera is prevented from any reflections from the environment thanks to black tissue and every element close to the camera is also covered by black tissue or painted with high emissivity black paint to avoid any residual reflection. 
Kinematic Measurements

Images of the sample are grabbed during the tests thanks to a Jai CV-M4+ CCD Camera. This camera is made of a matrix of 1368 by 1024 detectors sensitive to visible wavelengths from 0.38 to $1 \mu \mathrm{m}$; it delivers grayscale images and the dynamic range of digital levels is 10 bits. A Tamron 23FM50SP $50 \mathrm{~mm}$ lens associated to extension tubes enables a high spatial resolution of $6.5 \mu \mathrm{m} \times 6.5 \mu \mathrm{m}$ per pixel leading to a working zone of $\sim 8.9 \mathrm{~mm} \times 6.7 \mathrm{~mm}$. Although no spatial distortion near to the borders is observed, the working zone is reduced to $5 \mathrm{~mm} \times 5 \mathrm{~mm}$, in order to match the infrared data (see Thermal Measurements).

Displacement and strain fields are then obtained through DIC performed on the images captured during the mechanical deformation of the sample. The displacement field of one image is determined with respect to a reference image thanks to the DIC software Correli ${ }^{\text {LMT }}$ developed at LMT laboratory (Cachan, France). The principle is the following. The reference two-dimensional image is divided into square regions [called Zone of Interest (ZOI)]; then, the DIC software matches these ZOI between one image at a time $t_{\mathrm{i}}$ and the reference image at a time $t_{0}$, thanks to an algorithm based on Fast Fourier Transformation. ${ }^{[9]}$ The result of the DIC analysis is then a two-dimensional displacement field for each time $t_{\mathrm{i}}$. The principle of the correlation is based on pattern recognition. The pattern has to be randomly obtained and has to cover a wide range over the grayscale. In some particular cases, such a random pattern appears naturally on the tested material so that correlation can be performed directly on images of the raw material. For example, DIC was recently computed directly from images of the metallic phases of polished and electrochemically etched duplex steel. ${ }^{[10]}$ In more general cases, the pattern has to be created artificially: the sample is then usually covered with black and white paint in order to obtain a random speckle. In the present case, a coating has to be applied since the sample is polished as a mirror and the working scale is bigger than the one of El Bartali et al. ${ }^{[10]}$

\section{Fully-Coupled Measurements}

In order to get strain and temperature fields at the same time, a sample can be observed on one side with a CCD camera, in order to perform DIC, and on the other side with an IR camera, in order to determine its temperature. ${ }^{[1]}$ To process such data, it must be assumed that the thermal and kinematical responses are the same on each face of the sample. However, the objective of the present work is to get these data at the grain scale and to establish a link between them; thus the former method is not suitable since the microstructure is different from one face to the other. Therefore, it is necessary to observe the same area of the sample simultaneously with both IR and CCD cameras: this is the objective of the original coupling developed in this study.
In order to realize this simultaneous observation, a "filter-mirror", also known as dichroic mirror, is placed in front of the sample with an angle of $45^{\circ}$ with respect to the sample surface. On the one hand, this filter-mirror behaves like a filter since it only lets the infrared radiation go toward the IR camera placed ahead of the sample. On the other hand, it also behaves like a mirror since it reflects the rest of the radiation, among which the visible radiation, in the direction of the CCD camera (Fig. 1).

Thanks to this particular technique, the observation of the same zone simultaneously seems to be quite easy. Nevertheless the transmission of the infrared radiation is not complete; the filter has a transmission curve depending on the wavelength that has to be taken into account during the calibration. This implies that during calibration, the filtermirror has to be placed in front of the blackbody, exactly in the same configuration than for the tests.

The filter-mirror allows a simultaneous observation of the same zone and high magnification lenses give high spatial resolution images. However, reaching fully-coupled measurements supposes that the coating applied on the sample meet conditions for both DIC and IRT. As a matter of fact, DIC has to be performed on optical images of random and contrasted aspect, covering a large range of gray levels, whereas infrared measurements require to be performed on high emissivity objects, which can be obtained thanks to a dark and homogeneous coating. As a result, the coating must be a speckle when observed by the CCD camera as well as dark and homogeneous when observed by the IR camera. As a consequence, a special coating has been developed; it is suitable, at the working scale, for both techniques and thus permits fully-coupled measurements.

\section{Experimental}

\section{Specimen Material}

The choice of the material is also a crucial issue. First of all, the material thermal diffusivity (ratio of thermal conductivity to volumetric heat capacity) must be as low as possible so that heat generation is not dissipated nor homogenized too quickly with respect to the frame frequency of the IR camera. This is actually essential to be able to capture the thermal fields heterogeneities. Secondly, single phase steel is preferred as the thermal properties should be considered identical in all

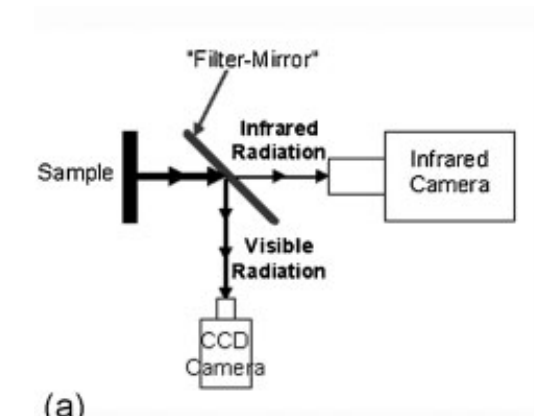

(a)

Fig. 1. Principle of the coupling thanks to the filter-mirror (a) and view of the experimental setup (b).

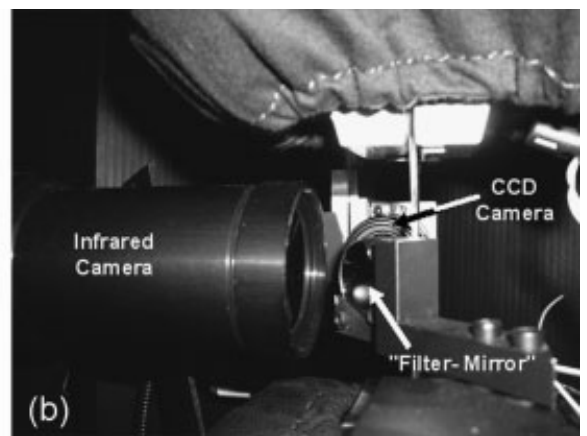



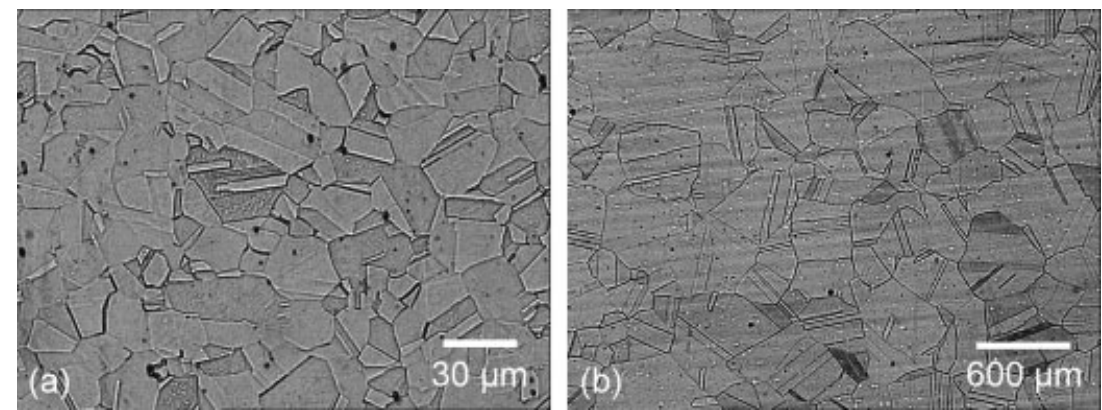

Fig. 2. Initial microstructure of AISI $316 \mathrm{~L}$ (a) and microstructure obtained after heat treatment, $1200^{\circ} \mathrm{C}$ for $2 \mathrm{~h}$ and water quench (b).

grains. Finally, the grain size has to be large enough so that several pixels of both IR and CCD matrixes can stare at one grain. This last condition leads us to use a material having a mean grain size of roughly $100 \mu \mathrm{m}$ (considering twins).

In order to respect as well as possible all the abovementioned constraints, the chosen material is an AISI 316L since it meets the two first criteria. Its initial grain size is of about $10 \mu \mathrm{m}$, which is not enough. However, in the case of AISI $316 \mathrm{~L}$, this size can easily be raised up to about $130 \mu \mathrm{m}$ thanks to a heat treatment at $1200^{\circ} \mathrm{C}$ for $2 \mathrm{~h}$, immediately followed by a water quench. Samples of the material before and after the heat treatment are chemically etched and examined under a microscope to underscore the grain growth (Fig. 2).

Specimens are $2 \mathrm{~mm}$ thick plates having a gage area of $10 \mathrm{~mm} \times 10 \mathrm{~mm}$. They are mechanically polished up to $1 \mu \mathrm{m}$ on faces and up to grit $4000 \mathrm{SiC}$ paper on the edges.

\section{Experiments}

Experiments are performed on an electro-mechanical Instron 4508 machine which enables tests up to $300 \mathrm{kN}$ on a speed range from 0.1 to $100 \mathrm{~mm} \mathrm{~min}^{-1}$. The test carried out in this work is a $2.8 \mathrm{~Hz}$ cyclic test at $R_{\sigma}=0.1$ leading to a maximum global deformation of 0.001 at the maximum stress.

During the test, displacement, strain, and temperature fields are recorded in the gage zone thanks to the full$y$-coupled measurement technique presented in the previous paragraphs. The load applied to the sample is also recorded during the tests.

In order to disturb as less as possible the thermal measurements, the working zone is protected from its environment as it has already been explained; light is turned off and the room temperature is kept steady thanks to air conditioned.

\section{Results}

The stresses due to the cyclic loading applied on the sample during the test are plotted in Figure 3.

Strain fields in the loading direction, corresponding to the instants marked A and B in Figure 3, are computed by DIC on a working zone of $5 \mathrm{~mm} \times 5 \mathrm{~mm}$ in the middle of the sample gage area. Here, DIC is performed on ZOIs of 16 by 16 pixels; this leads to a spatial resolution of $104 \mu \mathrm{m} \times$ $104 \mu \mathrm{m}$ as far as strain data are concerned.

Figure 4 illustrates the heterogeneity of the deformation with a range from 0 to 0.002 , which is the double of the mean deformation corresponding to the maximum stress $(0.001$ at $148 \mathrm{MPa})$. Even if heterogeneity looks identical on both fields of Figure 4, a finer comparison shows that the localization of the high levels of strains evolves: some zones undergo a higher deformation and others a lower one between instants A and B.

The heterogeneities of thermal fields captured at instants A and $\mathrm{B}$ cannot be related to the strain fields when observed at the naked eye. As a consequence, two points exhibiting extreme values of strain are chosen in Figure 4 and the time-filtered thermal evolutions versus time of the corresponding IR pixels are plotted in Figure 3.

The thermal evolutions of points 1 and 2 follow the same trend but with different levels. A phase opposition can be observed between thermal and stress signals of Figure 3. This phenomenon is linked to thermoelasticity. As a matter of fact, the temperature decreases as the sample is submitted to an increasing tensile stress and then increases again when the stress is diminishing.

\section{Discussion}

At instants A and B marked in Figure 3, the global deformation over the sample reaches its maximum value of 0.001 . The strain fields obtained at these instants exhibit heterogeneities: some areas are under low deformation with a strain value of 0.00025 whereas other areas are submitted to higher strains up to 0.002 . Points 1 and 2 are examples of this phenomenon. Considering the resolution of the strain fields, they are definitely in different grains. As a result these strain fields account for a different kinematic behavior from one grain to another. Moreover, the thermal behavior of these points is also different. As point 2 is submitted to a higher

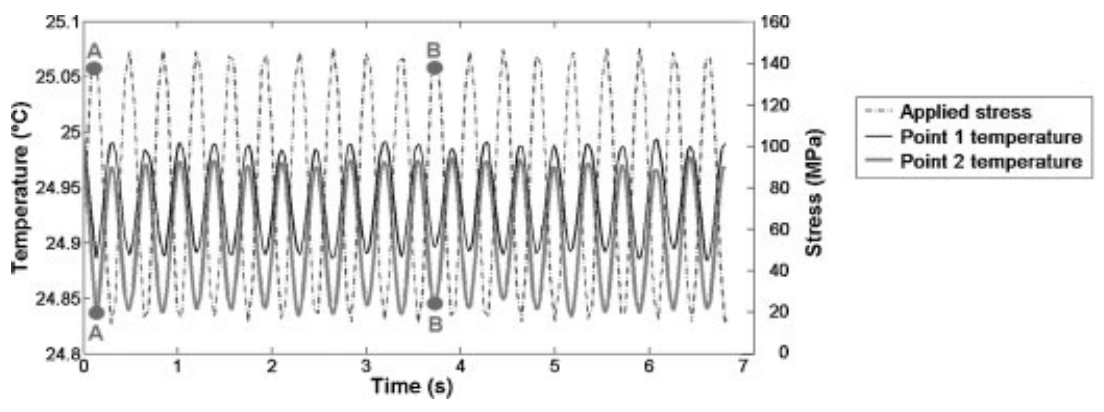

Fig. 3. Stress cycles versus time applied to the sample. Thermal evolutions versus time of points 1 and 2 of Figure 4. Points $A$ and $B$ correspond to the instants of the studied strain fields. 
(a)

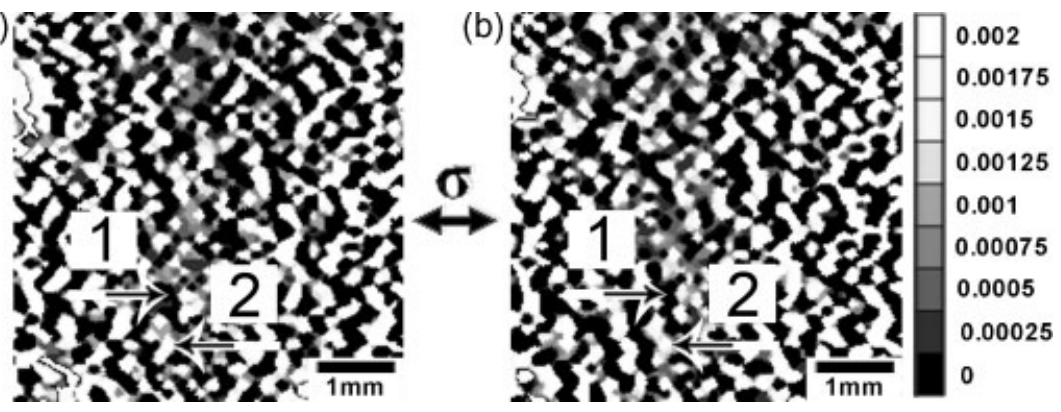

results of numerical simulations developed in the laboratory like polycrystalline aggregates models ${ }^{[12]}$ or simulations taking into account both thermoelasticity and thermoplasticity. ${ }^{[13]}$ The objective is finally to enhance local nonlinear constitutive laws in fatigue.

Fig. 4. Strain fields in the loading direction obtained by DIC at instants A (a) and B (b) of Figure 3, over a

$5 \mathrm{~mm} \times 5 \mathrm{~mm}$ zone within the gage area. Points 1 and 2 exhibit different levels of strain.

strain, its decrease is more important than the one of point 1 , hence its lower temperature at instants A and B. Following these instants, when the stress decreases, the temperature of point 1 is still lower since the strain relief can be assumed less important. As a consequence, the kinematic and thermal data observed in this test are typical from the deformation mechanisms which take place in a polycristal and which have been described in the introduction.

\section{Conclusion}

In this study and for the first time, fully-coupled kinematic and thermal measurements have been performed on a steel at the grain scale. The original setup developed shows that it is possible to highlight heterogeneities at this scale for both kinematic and thermal behaviors. This means that it is possible to get thermomechanical data of a Representative Volume Element of a polycristal, which can be further exploited for different purposes. On the one hand, if thermal fields are correctly processed within a thermomechanical framework, ${ }^{[6]}$ they give access to thermal sources and since strain fields of the same zone are also available, local energy balances can be realized at the grain scale. On the other hand, such information can also be used as a comparison point for
[1] A. M. Korsunsky, K. E. James, M. R. Daymond, Eng. Fract. Mech. 2004, 71, 805.

[2] M. P. Luong, Mech. Mater. 1998, 28, 155.

[3] F. Curà, G. Curti, R. Sesana, Int. J. Fatigue 2005, 27, 453.

[4] C. Doudard, S. Calloch, P. Cugy, A. Galtier, F. Hild, Fatigue Fract. Eng. Mater. Struct. 2005, 28, 279.

[5] T. Boulanger, A. Chrysochoos, C. Mabru, A. Galtier, Int. J. Fatigue 2004, 26, 221.

[6] B. Berthel, A. Chrysochoos, B. Wattrisse, A. Galtier, Exp. Mech. 2008, 48, 79.

[7] H. Pron, C. Bissieux, QIRT J. 2004, 1, 229.

[8] G. Gaussorgues, S. Chomet, Infrared Thermography, Chapman \& Hall, London 1994

[9] F. Hild, Appl. Opt. 2002, 41, 6815.

[10] A. El Bartali, V. Aubin, S. Degallaix, Fatigue Fract. Eng. Mater. Struct. 2007, 31, 137.

[11] A. Chrysochoos, J. M. Muracciole, B. Watrisse, Continuous Damage and Fracture, Cachan, France 2000, p. 41.

[12] P. Evrard, V. Aubin, P. Pilvin, S. Degallaix, D. Kondo, Mech. Res. Commun. 2008, 35, 336.

[13] L. Bodelot, L. Sabatier, E. Charkaluk, P. Dufrénoy, $8^{\text {ème }}$ Colloque National en Calcul des Structures, Hermes, Giens, France 2007, p. 41. 